\title{
Desafíos constitucionales de las ciudades inteligentes*
}

\section{Constitutional challenges of smart cities}

\author{
Rubén Enrique Rodríguez Samudio ${ }^{1 凶}$
}

* El autor agradece al Dr. José Hernán Muriel Ciceri del Instituto Tecnológico de Monterrey por la oportunidad de presentar una versión preliminar de este artículo a un pequeño grupo de profesionales y estudiantes bajo su cargo.

${ }^{1}$ Investigador, Universidad de Hokkaido, Japón. Profesor Adjunto, Universidad de Keio, Japón. Doctor en derecho, Universidad de Hokkaido, Japón.

Fecha correspondencia:

Recibido: marzo 24 de 2021.

Revisado: julio 06 de 2021.

Aceptado: julio 13 de 2021.

Forma de citar:

Rodríguez, Rubén Enrique.

"Desafíos constitucionales de las

ciudades inteligentes" En: Revista

CES Derecho. Vol. 12, No. 2, julio a

diciembre de 2021, p. 3-22.

https://dx.doi.org/10.21615/

cesder.6174

\section{Open access}

() Derecho de autor

Licencia creative commons

Ética de publicaciones

Revisión por pares

Gestión por Open Journal System

DOI: $10.21615 /$ cesder. 6174

ISSNe 2145-7719

Publica con nosotros

\section{Resumen}

Las ciudades inteligentes son un nuevo modelo de urbanismo que utiliza tecnologías de información y comunicación para analizar los datos personales a fin de solucionar problemas de administración municipal y mejorar el nivel de vida de los ciudadanos. Sin embargo, los modelos constitucionales occidentales están basados en una sociedad análoga, en la cual las interacciones se dan de manera presencial y donde la información ciudadana no es un elemento fundamental del modelo urbanístico. Particularmente, las constituciones con una fuerte protección de derechos individuales tienen la difícil tarea de balancear las garantías fundamentales con un esquema social que requiere del uso de datos ciudadanos. Igualmente, el rol de la empresa privada en una ciudad inteligente ya no se limita a la prestación de servicios, sino que, dependiendo del modelo, se extiende a labores de administración usualmente reservadas a entidades públicas. Este nuevo panorama implica la necesidad de replantearse las relaciones Estado-individuoempresa privada.

Palabras claves: ciudades inteligentes; constitucionalismo; privacidad; derechos individuales; derecho comparado. 


\section{Abstract}

Smart Cities are a new urbanism model that uses information and Communications Technologies to analyze personal to solve municipal administration problems and improve s citizens' lives. However, western constitutional models are based on an analog society, in which face-to-face interactions are the norm and where citizen's information is not fundamental to urbanism models. Particularly, constitutions with strong protections of individual rights have the difficult task of balancing these fundamental rights with a social structure that requires citizens' data. In addition, the private sector role within Smart Cities is no longer limited to providing services, but, depending on the model, also includes administrative tasks usually reserved to the government. This new perspective requires a rethinking of the relationship between state, individual, and corporations.

Keywords: smart cities; constitutionalism; privacy; individual rights; comparative law.

\section{Introducción}

Este artículo ofrece algunas reflexiones sobre los desafíos constitucionales de un desarrollo social basado en la figura de las ciudades inteligentes, con particular énfasis en el papel del Estado y la empresa privada. En un estado de derecho la constitución se constituye en el pilar que fundamenta el desarrollo de cada sociedad en particular, estableciendo los deberes y derechos de los ciudadanos, así como las atribuciones y límites al poder estatal. Por ende, la influencia del pensamiento constitucional incide directamente en el modelo de urbanismo de cada Estado.

Los modelos de desarrollo urbano en torno a una sociedad conectada no es algo nuevo. Algunos autores como Cugurullo (2018) colocan los orígenes de las bases académicas del urbanismo inteligente en el siglo XV, particularmente en los escritos de Francis Bacon, sin embargo, el auge del urbanismo tecnológico inicia a finales del siglo XIX con la revolución industrial. A principios del siglo XX, comienzan a surgir los primeros modelos académicos de integración científica y desarrollo urbano y para la década de los años 50 el termino ciudad sostenible (Sustainable city) cobra auge en el campo del desarrollo urbano(Eremia et al., 2017, p. 14) .

A pesar de que el desarrollo de tecnologías de información y comunicación (TIC) necesarias para la implementación de un modelo urbano inteligente vio un auge tras la Segunda Guerra Mundial, su implementación se dio de manera diferente. Comparadas con las tecnologías de la 
revolución industrial, el modelo urbano basado en TIC, particularmente la conexión vía internet, es un concepto etéreo, enfocado en la miniaturización de dispositivos, por lo que su impacto es menos apreciable a simple vista (Cugurullo, 2018).

No obstante, algunos ejemplos de uso de macrodatos para la administración urbana a nivel local en Los Angeles en la década de los años 70 (Vallianatos, 2015), y los modelos de isla inteligente de Singapúr para finales de los años 80, el boom modelos de implementación de TIC en el desarrollo urbano se da en la década de los 90 con el crecimiento inteligente (Smart Growth) en Estados Unidos (Harrison \& Donnelly, 2011; Rosati \& Conti, 2016) o las ciudades digitales (Digital Cities) a nivel europeo (Eremia et al., 2017).

No es sino hasta finales de la primera década del siglo XXI que el termino ciudad inteligente comienza a usarse con regularidad. A pesar de esto, no existe una definición técnica de qué constituye una ciudad inteligente. Kitchin (2014) afirma que en la doctrina el termino tiene dos acepciones. La primera hace referencia al aspecto tecnológico de ciudad inteligente enfocándose en la implementación de tecnologías en los ambientes urbanos. La segunda acepción enfatiza el desarrollo económico de una región determinada, guiado por la innovación, creatividad, y el espíritu de emprendimiento. Kitchin considera que ambas definiciones están influenciadas por un ethos neoliberal que prioriza soluciones tecnológicas de mercado a problemas de gobernabilidad.

Otro sector de la doctrina se enfoca en los fines humanos de la ciudad inteligente, sin desconocer sus elementos tecnológicos o económicos. Por ejemplo, Woo(2017, p. 955) comenta que el objetivo de una ciudad inteligente es mejorar la vida de sus ciudadanos mediante la recolección, análisis, procesamiento, y transmisión de data. Finch y Tene (2014) advierten que las ciudades inteligentes prosperan en el flujo constante y omnipresente de datos capturados por cámaras y sensores instalados a lo largo del paisaje urbano. Estos dispositivos capturan todo tipo de comportamientos, que pueden ser agregados, almacenados y analizados para obtener conclusiones personales de los ciudadanos. Las ciudades inteligentes prometen mejorar el consumo energético a la vez que reducen costos económicos y ambientales mediante el uso de tecnologías como sensores, redes de macrodatos, transportes autónomos y energía renovable (Cugurullo, 2018).

Un sector importante de la doctrina se ha enfocado en los desafíos legales de la implementación de tecnologías inteligentes en el entorno urbano. Edwards (2016) identifica tres factores de riesgo en las ciudades inteligentes: el internet de las cosas, macrodatos y servicios de 
tecnologías en la nube. La privacidad es quizás el derecho más afectado por los modelos de urbanismo inteligente. Esto se debe a que el desarrollo del concepto de privacidad como derecho subjetivo va de la mano de las innovaciones tecnológicas de cada época. A diferencia de las tecnologías introducidas tras la revolución industrial, no existen barreras físicas para la recolección de datos en una ciudad inteligente, por lo que el derecho a la privacidad se desdibuja (Rodríguez, 2019).

Empero, las ciudades inteligentes no imponen desafíos únicamente en materia de privacidad. Como lo comenta Woo (2017, p. 956) este tipo de ciudades presentan una serie de desafíos únicos en materia de privacidad, seguridad y libertades individuales, no solo por la proliferación de sensores que colectan la información personal, sino también porque los ciudadanos comprenden los costos de algunos servicios como el WI-FI gratis.

Es en este tipo desafíos donde el pensamiento constitucional de cada país establece el marco general del desarrollo societal. Una constitución con fuertes protecciones a las libertades individuales se traduce en una mayor limitación a la capacidad del Estado de implementar tecnologías de recolección de datos. Si bien en muchos casos, estos desafíos pueden afrontarse mediante reformas legales, la realidad es que el progreso hacia una sociedad conectada ha cambiado aspectos fundamentales de la relación individuo-estado en una magnitud similar al cambio producto de la revolución industrial.

Sin embargo, también existe una crítica a un modelo constitucional que acepta la existencia de garantías individuales sin limitaciones; por cuanto no todos los individuos están dispuestos a colaborar con un desarrollo urbano, aun cuando su participación se de manera pasiva. Esto no debe entenderse necesariamente como una crítica a las garantías individuales presentes en el constitucionalismo occidental. Por el contrario, la voluntad de un Estado de encontrar puntos medios entre el uso de datos personales y las libertades individuales debe ser una de las metas de cualquier Estado moderno.

Este artículo aborda estos desafíos en cinco secciones. La segunda sección introduce una muy breve reseña de tendencias constitucionales modernas, haciendo una distinción entre el pensamiento constitucional occidental y su contraparte oriental, en particular en la materia en las obligaciones del individuo para con el Estado. La tercera sección discute el rol de las empresas privadas en la planificación desarrollo y administración de ciudades inteligentes y su 
relación con entidades estatales. La cuarta sección trata algunos temas de limitaciones constitucionales en materia de confianza del individuo hacia el estado, igualdad, y la labor del sector privado en el desarrollo de ciudades inteligentes.

\section{Constituciones para una sociedad conectada}

Antes de entrar en el tema objeto de estudio, es necesario establecer los límites del tema, particularmente en el ámbito del derecho comparado. En primer lugar, este artículo no trata sobre desafíos constitucionales en un país determinado. El pensamiento constitucional y la constitución sientan las bases de la relación entre desarrollo tecnológico colabora o riñe con las normas legales en cada país en particular. Sin embargo, debido a que existen de principios constitucionales comunes a los sistemas democráticos, o por lo menos a los sistemas democráticos occidentales o que hayan recibido influencia occidental es posible hablar de desafíos comunes a nivel de constitucionalismo comparado y derecho constitucional comparado.

En segundo lugar, y siguiendo el argumento de Tushnet (2008, p. 1230) este artículo hace una distinción entre derecho constitucional comparado y constitucionalismo comparado. De acuerdo con el autor la distinción radica en que el constitucionalismo comparado se enfoca en el estudio de elementos dogmáticos y de la protección de derechos individuales, en cambio el derecho constitucional comparado adopta una postura más amplia y práctica, enfocándose en aspectos como la organización del Estado mediante normas constitucionales concretas. Es por ello por lo que un régimen autoritario puede tener una constitución, pero no necesariamente un pensamiento constitucional.

Schütze (2019) explica como la doctrina le otorga diversas definiciones al termino constitucionalismo. El constitucionalismo descriptivo es, como lo expresa el termino, la descripción de las instituciones y poderes del gobierno. Por otra parte, el constitucionalismo normativo no se limita a un análisis descriptivo, sino que prescribe tales instituciones y funciones. El constitucionalismo material vincula el concepto de la constitución a una filosofía política particular con el fin de legitimarla. También existe una corriente que discute la posibilidad de un constitucionalismo global en el área del derecho internacional(Mogami, 2018). 
En lo que respecta al constitucionalismo normativo, Tushnet (2008, p. 1230) comenta que todos los sistemas a los cuales el termino les es aplicable deben satisfacer una serie de requerimientos mínimos, pero la manera en que esto sucede en la práctica varia de país en país. Estos elementos son: respeto por el estado de derecho, un órgano judicial independiente y por último elecciones libres y abiertas.

En el caso de Latinoamérica, siguiendo lo que la doctrina denomina constitucionalismo de derechos humanos (Gargarella, 2018, p. 110), las constituciones latinoamericanas de finales del siglo XX y principios del siglo XXI se han enfocado en una expansión del reconocimiento de derechos individuales y de minorías. Esto ha dado como resultado constituciones extensas con una robusta parte normativa. En este sentido, encontramos constituciones que siguen una doctrina de constitucionalismo material como las de Ecuador y Bolivia, enfocadas en los problemas de las minorías indígenas.

Aunque las constituciones latinoamericanas en teoría cumplen los requisitos de constitucionalismo normativo descritos por Tushnet, en la práctica la región no ha podido escapar de estigmas de corrupción. Hay relativamente pocos estudios enfocados en el impacto del número de normas constitucionales con el desarrollo de los países. De forma anecdótica, las constituciones de países desarrollados suelen ser cortas mientras que las de países en desarrollo suelen ser extensas. Tsebelis y Nardi (2016) analizan las constituciones del grupo de la OECD y llegan a la conclusión de que entre más extensa sea la constitución impone más restricciones y costos sociales. Los autores demuestran que una constitución extensa está vinculada a un menor PIB per cápita y generan más oportunidades para corrupción.

Independientemente de que las conclusiones de Tsebelis y Nardi, la realidad política, cultural y tecnológica de los países latinoamericanos es muy diferente a la de otras latitudes. Las constituciones latinoamericanas son extremadamente rígidas, enfocadas en partes normativas extensas, quizás con la esperanza de que una gran cantidad de normas exista disminuyan las posibilidades de corrupción estatal y den paso a un desarrollo social y económico., situación que a todas luces no ha dado resultado.

Desde la perspectiva del derecho comparado, las sociedades asiáticas muestran una imagen diferente de la constitución y el pensamiento constitucional. Si bien es cierto que los estándares democráticos occidentales vieron un auge durante el siglo $\mathrm{XX}$, y que dichos estándares forman el pilar de la mayoría de las sociedades en el siglo XXI, no todos los países que pueden considerarse como democracias se adhieren a ellos. Algunos países como Japón y 
Corea del Sur han mezclado sus entornos culturales a las ideas presentadas por un constitucionalismo normativo occidental. Otros países, representados por China, buscan un acercamiento en materia económica, comercial y tecnológica, mientras mantienen estándares constitucionales muy diferentes a los de occidentes.

Este artículo no es la plataforma adecuada para hacer un análisis doctrinario de las diferencias entre el constitucionalismo occidental y su contraparte oriental. Sin embargo, dos razones importantes hacen necesario hacer un breve recuento del pensamiento constitucional oriental. La primera es que muchos de los avances tecnológicos que hacen posible una ciudad o sociedad inteligente están siendo desarrollados en Asia. En efecto, como se discutirá posteriormente, las políticas de desarrollo de ciudades inteligentes en el occidente son muy diferentes a aquellas en países asiáticos. En segundo lugar, el eventual desarrollo a gran escala de sociedades inteligentes implica el choque de sistemas legales producto de la necesidad del flujo de datos. Por otra parte, en los últimos años, el número de contribuciones académicas en idiomas occidentales por parte especialistas en pensamiento constitucional oriental han aumentado considerablemente, lo que permite analizar un área poco estudiada en nuestro entorno. Algunos autores como Son (2016) analizan la cultura constitucional asiática desde raíces culturales como el confucionismo. Sin embargo, la región del sudeste asiático ha tenido múltiples reformas constitucionales, pero poco desarrollo constitucionalista(Dressel \& Bünte, 2016 , p. 6). entre los cuales encontramos que los sistemas asiáticos contienen similitudes y diferencias importantes en lo que se refiere a pensamiento constitucional comparado.

Este artículo hace énfasis en tres modelos constitucionales asiáticos: China, Japón y Corea del Sur. Dejando a un lado, por el momento, el tema de China, encontramos que el constitucionalismo asiático suele tener una idea muy distinta del concepto de órgano judicial independiente. La filosofía constitucional oriental enfatiza el rol del Estado como garante de un orden social en donde el individuo tiene obligaciones y deberes, a la par de ciertos derechos. La función de las cortes no es necesariamente limitar los poderes del Estado, sino que se centra en la conservación del orden social mediante la adjudicación de conflictos privados y la aplicación de normas penales. Las cortes orientales limitaran los poderes del estado en la medida que perturben estas reglas no escritas de conducta.

Inclusive en sociedades comparativamente occidentalizadas como lo son Corea del Sur y Japón, las cortes suelen ser sumamente conservadoras. En el caso de Japón, la Corte Suprema de Justicia solo ha declarado 11 normas inconstitucionales en más de 70 años de historia. Tal es la reticencia de las cortes niponas a declarar la inconstitucionalidad de una norma que la 
jurisprudencia ha creado el "estado de inconstitucionalidad" para cierto tipo de normas sensibles, principalmente aquellas que traten de temas políticos y electorales. Este tipo de sentencia no elimina la norma en cuestión por cuanto no ha sido declarada inconstitucional, su función principal es notificar al parlamento de que la norma tal como está redactada vulnera la letra o espíritu de la constitución, por lo que debe ser reformada, so pena de ser declarada inconstitucional.

Las constituciones de Corea del Sur y de Japón cumplen con los elementos descritos por Tushnet, aunque su desarrollo fue muy diferente. La constitución japonesa, redactada en gran parte por las fuerzas norteamericanas tras la guerra, introduce los conceptos democráticos a un pueblo que entro en la modernidad e industrialización de manera repentina a principios del siglo XX. Si bien la constitución japonesa reconoce derechos individuales de la misma manera que sus contrapartes occidentales, también impone límites y restricciones al ejercicio de estos. En particular, el artículo 12 del texto constitucional impone una obligación a sus ciudadanos de utilizarlos para el bien común y prohíbe el abuso de derechos constitucionales.

El caso coreano es distinto, al igual que en Japón, la constitución coreana fue promulgada tras la segunda guerra mundial. Sin embargo, el país sufrió una serie de revueltas sociales y políticas hasta la reforma de 1987, cuando se introdujeron cambios para una mayor participación ciudadana y un control constitucional de las leyes bajo la figura de la Corte Constitucional. El resultado, fue la elección del primer presidente civil en 1993, un boom económico y control constitucional que ha garantizado la democracia en este país. Igualmente, la constitución coreana limita el ejercicio de ciertos derechos cuando estos afecten el bien común. En particular, el artículo 37 establece que los derechos ciudadanos pueden limitarse por motivos de seguridad nacional, para la observancia de la ley y para proteger el bien común.

Por su parte, la constitución china es un ejemplo claro de constitucionalismo material. El artículo primero del texto constitucional chino establece que:

"La República Popular China es un Estado socialista bajo la dictadura democrática popular, dirigido por la clase obrera y basada en la alianza obrero-campesina.

El sistema socialista es el sistema básico de la República Popular China. Está prohibido el sabotaje por parte de cualquier organización o individuo contra el sistema socialista". ${ }^{1}$

\footnotetext{
${ }^{1}$ Traducción de https://www.constituteproject.org/constitution/China 2004.pdf?lang=es.
} 
La constitución china reconoce muchas de las garantías reconocidas en sus contrapartes occidentales con algunas notables excepciones, como lo es el artículo 10 que establece que el Estado es el titular de los derechos de propiedad sobre tierra urbana. De igual manera, las economías no públicas (léase el sector privado) debe desarrollarse en el contexto de una economía socialista de mercado, según lo establece el artículo 11 de la norma constitucional. Estos son solo algunos ejemplos de un sistema que reconoce derechos individuales solo en la medida que se compaginen con las ideas políticas del Estado.

Más allá de las discusiones doctrinarias sobre el reconocimiento o no de los derechos individuales en China, las diferencias constitucionales mencionadas impactan de manera directa el desarrollo de ciudades inteligentes en la región. En la práctica, el contrato social entre el gobierno chino y sus ciudadanos no es necesariamente el mismo al de otras naciones. Por una parte, los tres países asiáticos mencionados hacen énfasis en el orden social y el bien común como limitante a los derechos individuales de los ciudadanos. La diferencia trascendental entre la "dictadura democrática popular" y las dictaduras de Latinoamérica es que el modelo chino justifica mecanismos intrusivos en un desarrollo económico.

A diferencia de los modelos constitucionales orientales discutidos en esta sección, las constituciones occidentales no suelen desarrollar la idea de abuso de derechos constitucionales por parte de sus ciudadanos. Las constituciones latinoamericanas, producto del pacto liberalconservador, contienen normas para declarar estados de emergencia o de excepción. Sin embargo, estos son casos extremos diseñados para afrontar situaciones específicas y que no necesariamente buscan una armonía social.

\section{La empresa privada en una ciudad inteligente}

La discusión de la sección anterior no se limita al ámbito del constitucionalismo o del derecho constitucional comparado. Las diferencias culturales discutidas se extienden al rol del Estado dentro de la administración de una ciudad inteligente., sino que afecta directamente la implementación de políticas de urbanismo inteligente.

Angelidou (2014) comenta que en los países occidentales, las ciudades ya han alcanzado un nivel desarrollo que requiere un enfoque en la regeneración de áreas urbanas degradadas. En cambio, los países en desarrollo optan por la creación de nuevas ciudades diseñadas y construidas en base a la tecnología inteligentes. Las observaciones de Angelidou son ciertas en gran medida, con algunas excepciones. Por ejemplo, Corea del Sur y Japón son ciudades que siguen un modelo relativamente occidental producto de sus fuertes lazos con Estados Unidos. $\mathrm{xx}$ 
Ambos países han implementado tecnologías inteligentes en sus metrópolis urbanas, Seúl y Tokio respectivamente, sin dejar de lado la creación de ciudades inteligentes desde cero como lo son Songdo en Corea del Sur y la Woven City de Toyota en Japón.

En tanto, el plan de desarrollo occidental suele enfocarse en el modelo económico neoliberal de libre mercado, por lo que la participación de la empresa privada no se da necesariamente en una situación de subordinación. Los dispositivos necesarios para el desarrollo de una ciudad inteligente rara vez suelen provenir del sector público. Los primeros proyectos de ciudades inteligentes fueron iniciativas públicas en colaboración con entes privados, sin embargo, con el transcurso del tiempo el sector privado se ha posicionado entre los ciudadanos y los administradores de las ciudades inteligentes (Geffray \& Auby, 2017). Dameri (2017, pp. 23-24) expresa que las tecnologías utilizadas en una ciudad inteligente suelen desarrollarse en universidades, para luego ser comercializadas por el sector privado en colaboración con el entidades públicas.

El nivel de colaboración es importante por cuanto actualmente no existe una ciudad inteligente $100 \%$ privada, aunque ciudades como Songdo en Corea del Sur son administradas en su mayoría por una participación público-privada en donde el gobierno tiene una minoría de acciones. Este nivel de control por parte de un ente privado en lo que es efecto una de las funciones del Estado puede llegar a afectar las bases de la relación ciudadano-gobierno de manera nunca vista.

Si bien, la cooperación entre los sectores público y privado es un pilar fundamental de cualquier economía moderna, no queda claro si los servicios proporcionados por entes privados deben verse como contratos privados. Sadowski y Bendor (2019) revelan como en la ciudad de Songdo el negocio de la creación e instalación de las tecnologías necesarias para el funcionamiento de la ciudad está en manos de dos compañías: IBM y Cisco. Este nivel de integración de la empresa privada supera los modelos de colaboración tradicionales por medio de concesiones, lo que conlleva problemas de transparencia y responsabilidad sobre el manejo de recursos públicos.

El dilema radica en el hecho de que, bajo el sistema económico imperante, la principal función de la empresa privada es la obtención de ganancias. Aunque existen modelos de desarrollo sostenible y colaboración empresa privada-gobierno, la realidad es que la empresa privada requiere de utilidades para poder sobrevivir. En un entorno donde la administración de gran parte de sistemas y servicios municipales estén en manos de entes privados, surge la pregunta de cómo balancear la naturaleza capitalista del sector privado con la función social del Estado. 
Empero, no se trata de problemas bajo el modelo actual de concesiones a empresas privadas. En estos modelos, la empresa adquiere la obligación de prestar un servicio o desarrollar un proyecto bajo el auspicio y la vigilancia de órganos estatales. El dilema de los nuevos sistemas de urbanismo inteligente se da en la medida en que el rol de la empresa privada deja de ser un simple proveedor de servicios a un administrador equiparable a entes públicos. En estas circunstancias no queda claro como balancear el deber e la empresa para con sus accionistas con sus nuevas obligaciones como administrador de servicios estatales integrados.

En la medida que los gobiernos utilicen las tecnologías inteligentes para mejorar la administración de la ciudad y elevar el nivel de vida de sus ciudadanos surgen una serie de obligaciones que no se ven plasmadas en un texto constitucional, pero que resultan de la nueva relación información-urbanismo. Un ejemplo claro seria la obligación de administrar la cosa pública de manera eficiente que se encuentra en muchas constituciones. No está claro si tal obligación constitucional se extiende a la empresa privada, en la medida que administre una ciudad en conjunto con el sector público.

Cuando los municipios o gobiernos nacionales eligen una nueva tecnología, el contexto en el que se usará la información es de suma importancia pues ésta es la base en la cual se fundamenta el desarrollo de la ciudad; por eso, los gobiernos deben alinear sus políticas con el interés comunal al momento de elegir los datos a recolectar(Whittington, 2017, p. 928). No obstante lo anterior, los contratos relativos a proyectos de ciudades inteligentes suelen ser abiertos, sin estipulaciones específicas sobre el uso o propiedad de los datos recolectados (Keymolen \& Voorwinden, 2020, pp. 245-246).

Otro desafío surge en el caso de malos manejos o incumplimiento por parte del sector privado. Bajo los esquemas tradicionales de concesión el Estado tiene una serie de garantías ante la empresa administradora que le permite llevar a cabo el servicio público en caso de fallas graves. Sin embargo, en una ciudad inteligente diseñada y construida por el sector privado, no está claro en qué medida puede el Estado ejercer esta función fiscalizadora. En particular, surgen inconvenientes si la empresa privada ha utilizado software o hardware propietario para el diseño, construcción y ejecución de los proyectos de ciudades inteligentes.

La otra cara de la moneda puede observarse en el modelo implementado por el gobierno chino en base a su amplio poder constitucional. El proceso de urbanización tecnológica en China inicia a mediados de la década de los 90(Yang \& Xu, 2018, p. 535), ayudado por la propiedad de la tierra urbana por parte del gobierno chino. Este boom de desarrollo urbano, unido a la creación 
de infraestructura ferroviaria, tecnológica y políticas educativas le ha permitido llevar a cabo más de 500 proyectos de ciudades inteligentes a 2018 (Xinhua, 2018). Una diferencia importante entre el modelo occidental y el modelo chino es la función de la empresa privada. En China, el Estado suele tener una participación importante en la empresa privada, por lo que puede ejercer un control tanto interno y externo sobre una empresa.

Otra característica esencial del modelo chino es la creación del Sistema de Crédito Social, una política que busca medir los niveles de integridad social, civil y financiera mediante la recolección de información personal de los ciudadanos, va en contra de principios fundamentales del constitucionalismo occidental. Información sobre este sistema comenzó a circular en 2014 con una implementación a nivel nacional planeada para el año 2020, pero la pandemia parece haber retrasado su puesta en marcha a gran escala. A grandes rasgos, el sistema busca promover lo que el gobierno considera "conductas económicas y morales positivas", principalmente valores socialistas, respeto a los mayores y trabajo duro, y utiliza información personal para crear un puntaje ciudadano basado en elementos como situación financiera, récord policivo y conducta en las redes sociales(Kshetri, 2020). El sistema se basa en tres pilares: listas negras a nivel nacional, crédito social medido por instituciones financieras, puntaje de cumplimiento a nivel de ciudades (Mac Síthigh \& Siems, 2019).

El sistema de listas negras busca promover conductas positivas mediante la prohibición del uso de servicios como transporte aéreo o ferroviario, a la vez de las repercusiones financieras que pueda tener. La lista es de acceso público y es utilizada por entidades públicas y financieras para determinar el acceso a ciertos tipos de ayuda económica. A nivel local, el sistema de puntaje de cumplimiento es utilizado por las entidades municipales para decidir el acceso a ayuda económica y subsidios de vivienda, licencias de negocios y participación en licitaciones públicas.

El sector privado, ya sea nacional o extranjero, tiene pocas o ningunas opciones de oponerse a las políticas del gobierno chino. A finales el año 2020 el gobierno publicó una serie de guías dirigidas al sector privado para reforzar la ideología comunista $(\mathrm{He}, 2020)$. Yang \& Xu explican que los ciudadanos chinos se encuentran en una encrucijada, entre políticas de planeamiento urbano que incorporan sus conductas en la planificación urbana y un Estado de vigilancia que acumula información sobre una vasta gama de sus actividades(Yang \& Xu, 2018, p. 537). En 2017 hubo reportes de que el gobierno chino ha iniciado esfuerzos para crear una base de datos del ADN de sus ciudadanos, en particular hombres(Cyranoski, 2020). 
Este nivel de control no es posible bajo una constitución de corte occidental con énfasis en un sistema de derechos individuales. Si bien la integración de sistemas sociales para la obtención del bien común es un objetivo laudable, la intervención absoluta del Estado sobre la vida de sus ciudadanos pertenece al reino de la novela orwelliana y no a un estado de derecho. Las diferencias entre los diversos modelos de constitucionalismo pueden concluir en conflictos reales a nivel de diplomacia internacional.

\section{El ciudadano ante el Estado}

Cuando el constitucionalismo occidental habla de derechos individuales lo hace bajo la premisa de que la relación individuo-estado no es una de igualdad, sino de subordinación del estado hacia el individuo, a pesar del poder del primero. Sin embargo, esta subordinación no puede ser absoluta. En la medida que diversos derechos individuales se contraponen entre sí, la función del Estado se extiende a proporcionar un balance entre todos ellos.

En este sentido, las sociedades inteligentes enfrentan dos problemas fundamentales bajo el constitucionalismo normativo occidental que no se encuentran bajo el pensamiento constitucional oriental. El primero es el nivel de confianza del individuo hacia el Estado, en particular al uso de sus datos personales y posibles limitaciones a sus derechos individuales. Zoonen (van Zoonen, 2016, p. 474) comenta como varios estudios demuestran que los ciudadanos realizan un análisis costo-beneficio al momento de proporcionar sus datos personales. En la medida que los datos proporcionados se traduzcan en un beneficio personal apreciable y concreto (salud, ganancias económicas) los ciudadanos muestran mayor disposición a entregar sus datos. Por otra parte, cuando los beneficios se dan a un nivel más abstracto existe los ciudadanos muestran una renuencia proporcionar sus datos personales.

Particularmente en lo que respecta a los países latinoamericanos, las constituciones no están diseñadas para afrontar los desafíos de una sociedad conectada. La mayoría de las constituciones latinoamericanas contienen una gran cantidad de derechos individuales. Siguiendo las conclusiones de Zoonen, en la medida que los ciudadanos no perciban que reciben un beneficio apreciable directo es muy poco que el nivel de confianza hacia el Estado mejore aun en una sociedad inteligente.

La desconfianza a los entes estatales no es algo inherente a las sociedades latinoamericanas. La diferencia radica en la historia de corrupción que arrastran muchos de nuestros países. Debido a que el nivel de tolerancia del individuo hacia intervenciones del Estado en sus derechos civiles y políticos está íntimamente ligado a patrones culturales de conducta que escapan el ámbito 
del estudio de lo jurídico. Siguiendo la historia, no sería de extrañar que la solución que se planteen los países latinoamericanos sea una reforma constitucional. En el caso particular de las ciudades inteligentes, constituciones con una gran cantidad de derechos individuales y colectivos limitan las opciones disponibles al gobierno para buscar mecanismos de modernización.

La importancia de la relación de confianza del individuo hacia el Estado puede observarse en las limitaciones a la libertad de tránsito producto de la pandemia Covid-19. En Corea del Sur el gobierno optó por una política basada en el autoaislamiento y la cuarentena de edificios o áreas específicas dentro de las ciudades afectadas en conjunto con el rastreo de casos mediante el uso de datos proporcionados por dispositivos inteligentes, sensores, transacciones de tarjetas de crédito, información de inmigración, cámaras de vigilancia y demás datos personales para localizar a individuos que hayan tenido contacto con personas contagiadas(Aljazeera, 2020).

En cambio, el gobierno chino impuso restricciones a los ciudadanos de Wuhan, capital de la provincia de Hubei, epicentro de la actual pandemia. Esta política paso de ser inicialmente objeto de críticas por medios noticieros y organismos de derechos humanos en occidente a convertirse en el standard para control de contagios en muchos países. Sin embargo, la otra cara de la moneda son las limitaciones extremas a la libertad de expresión dentro del territorio chino, con especial atención a la respuesta inicial del gobierno local de Wuhan, posteriormente adoptada por el gobierno central chino, de limitar la información disponible y censurar a individuos que pudieran perjudicar la imagen del gobierno (BBC, 2020) .

Ambos son ejemplos de control social en base al uso de tecnologías inteligentes integradas al entorno urbano. La importancia para el derecho, y en particular el derecho constitucional, no radica en la eficacia científica de prevención del contagio, sino en el balance entre intereses individuales y sociales en un entorno de confianza hacia las entidades públicas versus uno de control absoluto.

También existen puntos medios, como sucede con el sistema de número personal creado por el gobierno de Japón. En el 2015 el gobierno japonés introdujo un sistema de identificación personal conocido como My Number, mediante el cual todo residente de Japón, incluyendo algunos extranjeros, reciben un número de 12 cifras mediante el cual pueden realizar varios trámites administrativos. A pesar de los esfuerzos del gobierno por promocionar el sistema, tras cinco años de su implementación solo un $25 \%$ de los residentes han hecho los trámites necesarios. Esta reticencia del pueblo japonés no nace necesariamente de una desconfianza 
hacia al gobierno, sino de la falta de un beneficio tangible para una población que ya está acostumbrada a un desarrollo tecnológico sin la conciencia de la manera en que sus datos están siendo utilizados.

El segundo problema fundamental es la protección a los derechos sociales como la educación, la salud o el acceso a la información pública. Las constituciones modernas, incluyendo la china, reconocen el principio de igualdad de los ciudadanos y les imponen a los estados la obligación de velar por la salud, la seguridad, educación y demás derechos sociales. El desafío se encuentra no en la violación directa de alguno de estos derechos, sino en la brecha digital que puede surgir entre ciudades inteligentes y aquellas que no lo sean.

Estas divisiones entre metrópolis y áreas rurales existen en cualquier sociedad, independientemente de su marco constitucional o prosperidad económica. Sin embargo, una sociedad fundamentada en tecnologías inteligentes corre el riesgo de expandir la brecha al punto de crear ciudadanos de segunda categoría. Nuevamente usando el ejemplo de la pandemia de covid-19, el uso de tecnologías digitales en el salón de clases ha dado como resultado una brecha palpable entre regiones con una conexión de internet adecuada y aquellas que no cuentan con este servicio.

Las brechas producto del uso de TIC son quizás uno de los desafíos más importantes del estado de derecho moderno. Por ejemplo, un sistema de transporte urbano basado exclusivamente en el uso de aplicaciones vía teléfonos inteligentes excluye a poblaciones que no cuenten con el acceso a estas tecnologías (Woo, 2017, p. 956). La inclusión de un derecho constitucional a la internet solo serviría para incrementar el gasto público sin que ello implique un beneficio inmediato para los ciudadanos.

Una posible solución podría ser la inclusión de un derecho a Internet. En efecto, a nivel de derecho internacional, existe una corriente que propugna incluir el acceso a Internet, o en sentido más amplio derecho a la información, entre la lista de derechos humanos. El argumento no es nuevo. Inclusive para principios del milenio, autores como Best (2004) propugnaban por un derecho a la información, del cual el acceso al internet es un elemento sine qua non.

Sin embargo, aunque tal derecho sea añadido al repertorio de derechos constitucionales, su implementación en la práctica no está asegurada. Antes de hablar de un derecho constitucional al acceso a internet los estados modernos tienen que enfrentar el problema alfabetización digital de manera que todos los ciudadanos puedan utilizar los servicios públicos libremente. 
El constitucionalismo normativo de corte occidental, con su énfasis en la protección de derechos individuales sin una clara subordinación hacia el bien común también se constituye en una limitante para la implementación de políticas en base a tecnologías inteligentes. EI Estado moderno tiene la ardua tarea de balancear políticas públicas con ciudadanos cada vez más conscientes del poder que ejercen sobre las mismas. En la medida en el Estado requiera una participación ciudadana, ya sea directa o por medios pasivos como la utilización de los datos personales, los problemas de igualdad y confianza hacia los entes públicos cobran importancia.

\section{Conclusiones}

Las ciudades inteligentes son uno de los nuevos desafíos del constitucionalismo moderno. Los principios fundamentales del pensamiento constitucional son la base sobre la cual se diseñan las políticas de urbanismo inteligente. Las escuelas de pensamiento occidental, con su énfasis en libertades individuales y la oriental, que propugna por un orden social estable, se ven reflejadas en las políticas y planes de desarrollo de ciudades inteligentes.

Bajo este nuevo modelo de desarrollo urbano la empresa privada adquiere un rol que tradicionalmente ha sido reservado para entes estatales. No se trata de una simple administración de recursos mediante esquemas de concesiones, sino de función íntimamente ligada al funcionamiento de los órganos del Estado como tal. Este nuevo modelo de cooperación requiere de un replanteamiento de la posición que ocupan las grandes empresas dentro del engranaje social. Las empresas que adquieran la tarea de administrar las ciudades inteligentes se encuentran ante una situación contradictoria, en la que deben balancear sus obligaciones para con sus accionistas con los deberes inherentes a la función pública que ejercen.

Por otra parte, el Estado también tiene sus desafíos particulares. Especialmente en los países latinoamericanos, con su tendencia a redactar constituciones con extensas obligaciones estatales y pocas limitantes al abuso de derechos constitucionales por parte de los ciudadanos, no están equipados de manera adecuada a una sociedad que requiere de una cooperación para poder funcionar de manera adecuada. Esto se debe a que la constitución le impone al Estado una serie de obligaciones específicas que en muchas ocasiones no son compatibles con la idea de una sociedad conectada, especialmente cuando estas obligaciones se traducen en políticas que otorgan un beneficio abstracto a sus ciudadanos. 
Julio - diciembre de 2021

La tarea de los países occidentales, y en particular para los modelos constitucionales, es crear un desarrollo urbano donde los ciudadanos están dispuestos a entregar sus libertades individuales sin temor a un Estado dictatorial. La respuesta para superar este obstáculo radica en el nivel de confianza que el Estado pueda inspirar en sus ciudadanos. Para la implementación de políticas de urbanismo y gobierno inteligente es necesario que el individuo comprenda sus derechos y obligaciones como parte de un todo, y que observe beneficios puntuales por el cumplimiento de sus obligaciones constitucionales.

\section{Referencias}

Aljazeera. (2020, March 10). How Italy, South Korea differ in tackling coronavirus outbreak |Coronavirus pandemic News| Al Jazeera. ALJAZEERA. https://www.aljazeera.com/news/2020/3/13/how-italy-south-korea-differ-intackling-coronavirus-outbreak

Angelidou, M. (2014). Smart city policies: A spatial approach. Cities. https://doi.org/10.1016/i.cities.2014.06.007

BBC. (2020). China Covid-19: How state media and censorship took on coronavirus - BBC News. BBC. https://www.bbc.com/news/world-asia-china-55355401

Best, M. L. (2004). Can the Internet be a Human Right? Human Rights \& Human Welfare, 4, 23-31.

Cugurullo, F. (2018). The origin of the smart city imaginary: From the dawn of modernity to the eclipse of reason. In The Routledge Companion to Urban Imaginaries. https://doi.org/10.4324/9781315163956

Cyranoski, D. (2020). China's massive effort to collect its people's DNA concerns scientists. Nature. https://doi.org/10.1038/d41586-020-01984-4

Dameri, R. P. (2017). Smart City Implementation: Creating Economic and Public Value in Innovative Urban Systems. In Progress in IS,.

Dressel, B., \& Bünte, M. (2016). Contesting constitutionalism: Constitutional politics in southeast Asia. In Politics and Constitutions in Southeast Asia. https://doi.org/10.4324/9781315726687 
Edwards, L. (2016). Privacy, Security and Data Protection in Smart Cities: a Critical EU Law Perspective. European Data Protection Law Review, 2(1), 28-58.

Eremia, M., Toma, L., \& Sanduleac, M. (2017). The Smart City Concept in the 21st Century. Procedia Engineering, 12-19. https://doi.org/10.1016/i.proeng.2017.02.357

Finch, K., \& Tene, O. (2014). Welcome to the Metropticon: Protecting Privacy in a Hyperconnected Town. Fordham Urban Law Journal, 41, 1581-1615.

Gargarella, R. (2018). Sobre el "nuevo constitucionalismo latinoamericano." Revista Uruguaya de Ciencia Política, 27(1), 109-129. https://doi.org/10.26851/rucp.27.5

Geffray, E., \& Auby, J. B. (2017). The political and legal consequences of smart cities. Field Actions Science Report, Special Issue 16, 11-15.

Harrison, C., \& Donnelly, I. A. (2011). A theory of smart cities. 55th Annual Meeting of the International Society for the Systems Sciences 2011.

He, L. (2020, September 22). Xi Jinping wants China's private companies to fight alongside the Communist Party - CNN. CNN. https://edition.cnn.com/2020/09/22/business/china-private-sector-intl$\underline{\mathrm{hnk} / \mathrm{index} \cdot \mathrm{html}}$

Keymolen, E., \& Voorwinden, A. (2020). Can we negotiate? Trust and the rule of law in the smart city paradigm. International Review of Law, Computers and Technology, 34, 233253. https://doi.org/10.1080/13600869.2019.1588844

Kitchin, R. (2014). The real-time city? Big data and smart urbanism. GeoJournal, 79(1), 1-14. https://doi.org/10.1007/s10708-013-9516-8

Kshetri, N. (2020). China's Social Credit System: Data, Algorithms and Implications. IT Professional. https://doi.org/10.1109/MITP.2019.2935662

Mac Síthigh, D., \& Siems, M. (2019). The Chinese Social Credit System: A Model for Other Countries? Modern Law Review. https://doi.org/10.1111/1468-2230.12462 
Mogami, T. (2018). Perpetuum Mobile Before and After Global Constitutionalism. In T. Suami, A. Peters, M. Kumm, \& D. Vanoverbeke (Eds.), Global Constitutionalism from European and East Asian Perspectives (pp. 29-57). Cambridge University Press.

Rodriguez Samudio, R. (2019). Privacidad en la Ciudades Inteligentes. Revista CES Derecho, 10, 675-695.

Rosati, U., \& Conti, S. (2016). What is a Smart City Project? An Urban Model or A Corporate Business Plan? Procedia - Social and Behavioral Sciences. https://doi.org/10.1016/i.sbspro.2016.05.332

Sadowski, J., \& Bendor, R. (2019). Selling Smartness: Corporate Narratives and the Smart City as a Sociotechnical Imaginary. Science Technology and Human Values, 44(3). https://doi.org/10.1177/0162243918806061

Schütze, R. (2019). Constitutionalism(s). In R. Masterman、 \& R. Schütze (Eds.), The Cambridge Companion to Comparative Constitutional Law (pp. 40-66).

Son, B. N. (2016). Confucian Constitutionalism in East Asia. Routledge.

Tsebelis, G., \& Nardi, D. J. (2016). A Long Constitution is a (Positively) Bad Constitution: Evidence from OECD Countries. In British Journal of Political Science. https://doi.org/10.1017/S0007123414000441

Tushnet, M. (2008). Comparative Constitutional Law. In M. Reimann \& Z. Reinhard (Eds.), The Oxford Handbook of Comparative Law (pp. 1225-1257).

Vallianatos, M. (2015, June 16). Uncovering the Early History of "Big Data" and the "Smart City" in Los Angeles - Boom California. Boom California. https://boomcalifornia.org/2015/06/16/uncovering-the-early-history-of-big-data-andthe-smart-city-in-la/

Van Zoonen, L. (2016). Privacy concerns in smart cities. Government Information Quarterly. https://doi.org/10.1016/i.giq.2016.06.004 
Whittington, J. (2017). Remembering the Public in the Race to Become Smart Cities. Remembering the Public in the Race to Become Smart Cities, 85(4), 925-930.

Woo, J. (2017). Smart Cities Pose Privacy Risks and Other Problems, But that Doesn't Mean We Shouldn't Build Them. University of Missouri-Kansas City Law Review, 85, 953-971.

Xinhua. (2018, February 20). China outnumbers other countries in smart city pilots: report Xinhua | English.news.cn. Xinhua. http://www.xinhuanet.com/english/2018$\underline{02 / 20 / c \quad 136987058 . h t m}$

Yang, F., \& Xu, J. (2018). Privacy concerns in China's smart city campaign: The deficit of China's Cybersecurity Law. Asia and the Pacific Policy Studies, 5, 533-543. https://doi.org/10.1002/app5.246 